\title{
Low dose of flurbiprofen axetil decrease the rate of acute kidney injury after operation: a retrospective clinical data analysis of 9915 cases
}

Dong Wang ${ }^{1 \dagger}$, Shi-Kun Yang ${ }^{2+}$, Meng-Xi Zhao ${ }^{1}$, Yong-Zhong Tang ${ }^{1}$, Wen OU-Yang ${ }^{1}$, Hao Zhang ${ }^{2}$ and Qin Liao ${ }^{1 *}$ (I)

\begin{abstract}
Background: Flurbiprofen axetil ( $F A)$ is a commonly prescribed agent to relieve perioperative pain, but the relationship between FA and postoperative acute kidney injury (AKI) remains unclear. This study attempted to evaluate the effects of different dose of perioperative FA on postoperative AKI.

Methods: A total of 9915 patients were enrolled for this retrospective study. The clinical characteristics and the prevalence of postoperative AKI among patients non-using, using low dose (50-100 mg), middle dose $(100-250 \mathrm{mg})$ and large dose $(\geqq 250 \mathrm{mg})$ of FA were analyzed respectively. The impact of different dose of FA on postoperative AKI was analyzed using univariable and multivariate logistic regression analysis.

Results: The prevalence of postoperative AKI was $6.7 \%$ in the overall subjects and $5.1 \%$ in 2446 cases who used FA. The incidence of AKI in low dose group was significantly less than that of non use group (4.5\% vs $7.2 \%, P<0.001$ ), but the incidence of AKI in large dose group was significantly higher than that in the nonuse group $(18.8 \%$ vs $7.2 \%, P<0.001)$. However, there was no significant difference between patients without using FA and subjects using middle dose of FA ( $7.2 \%$ vs $5.6 \%, p=0.355)$. Multivariate logistic regression analysis showed that low dose of FA was a protective factor for postoperative AKI $(\mathrm{OR}=0.75, p=0.0188)$, and large dose of FA was a risk factor for postoperative $A K I(O R=4.8, p<0.0001)$.

Conclusions: The impact of FA on postoperative AKI was dose-dependent, using of low dose FA (50-100 mg) perioperatively may effectively reduce the incidence of postoperative AKI.
\end{abstract}

Keywords: Flurbiprofen, Acute kidney injury, Operation, Retrospective study

\section{Background}

Acute kidney injury (AKI) is a syndrome with characteristic of the rapid loss of the renal function. AKI has a frequency of $1.9 \%$ in all hospital inpatients and is especially common in intensive-care unit of sepsis patients, in whom the prevalence of AKI is more than 40\% [1]. Postoperative AKI is a common complication in various operation patients, and it occurs in approximately $6.3-7.4 \%$ of patients who undergo noncardiac surgery $[2,3]$. It is associated

\footnotetext{
* Correspondence: xy3yyliaoqin@sina.com

†Dong Wang and Shi-Kun Yang contributed equally to this work.

1 Department of Anesthesiology, The Third Xiangya Hospital of Central South

University, 138, Tongzipo Road, Changsha, Hunan, China

Full list of author information is available at the end of the article
}

with adverse outcomes including prolonged mechanical ventilation and high morbidity. Recently, numerous studies have investigated the pathogenesis for AKI after surgery, the present evidence indicates that the pathogenesis of postoperative AKI is mainly related to haemodynamic injury, systemic inflammation, renal hypoxia, ischemiareperfusion injury and oxidative stress [4], and direct nephrotoxicity effects on the renal proximal tubule epithelial cells by various medication (e.g. iodinated contrast material, aminoglycoside antibiotics) is a vital cause for postoperative AKI, additionally, fluid depletion, renal neuroendocrine response to anesthesia and surgery itself are important reasons for postoperative AKI $[5,6]$.

(C) The Author(s). 2020 Open Access This article is distributed under the terms of the Creative Commons Attribution 4.0 International License (http://creativecommons.org/licenses/by/4.0/), which permits unrestricted use, distribution, and 
Flurbiprofen axetil (FA) is an injectable nonselective cyclooxygenase (COX) inhibitor. It can selectively accumulate in surgical incision and inflammatory site to reduce the inflammation and pain because of composed emulsified lipid microspheres [7]. Perioperative intravenous administration of FA has been reported to be associated with a reduction of postoperative pain. Nonsteroidal anti-inflammatory drugs (NSAIDs) are known to affect renal function in susceptible patients by inhibiting the synthesis of vasodilating renal prostaglandins [8]. Previous studies have indicated that FA could ameliorate renal injury in the rats with $5 / 6$ kidney ablation $[9,10]$, but some clinical data have showed that FA could induce renal papillary necrosis [11], and even acute tubulointerstitial nephritis [12]. However, a 52-week long time clinical study found that the effect of long-term FA application on renal function was small and subclinical [13]. Furthermore, the correlation between the effect of FA for perioperative analgesia on renal function and the range of dose safety is unclear. In order to explore the exact effects of FA on postoperative AKI, we performed this large retrospective study to guide future clinical applications of FA.

\section{Methods}

\section{Participants and design of study}

This was a retrospective clinical investigation of operation patients performed in the third Xiangya hospital of Central South University. We retrospectively reviewed medical records of all operation patients admitted from January 2012 to July 2017. The exclusion criteria were as follows: (1) subjects with age younger than 18 years. (2) subjects with any sepsis disease (e.g. urinary tract infections), tuberculosis. (3) subjects with acquired immune deficiency syndrome, or cancer. (4) all patients who underwent heart surgery or urologic surgery (including renal transplantion). (5) operation patients only using local anesthesia. (6) critically ill patients whose American Society of Anesthesiologists (ASA) grade was IV or V. (7) subjects with data missing of urine volume and serum creatinine $(\mathrm{Scr})$. The ethics committee of the third Xiangya Hospital of Central South University has approved this study.

\section{Flurbiprofen axetil administration}

The eligibility of the candidate was defined as those operation individuals who did not use any other NSAIDs

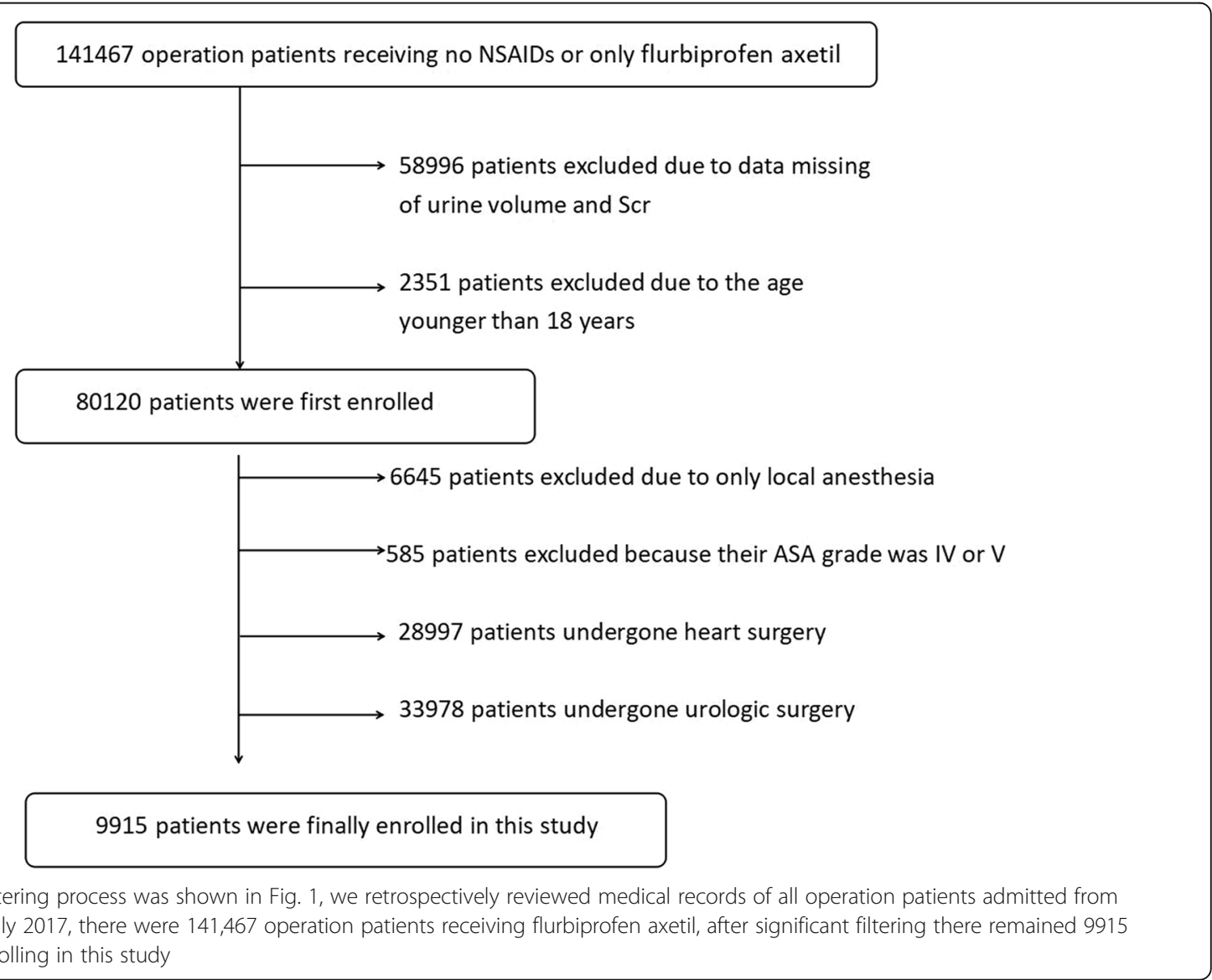

Fig. 1 The data filtering process was shown in Fig. 1, we retrospectively reviewed medical records of all operation patients admitted from January 2012 to July 2017, there were 141,467 operation patients receiving flurbiprofen axetil, after significant filtering there remained 9915 patients finally enrolling in this study 
except FA during the perioperative period. Patients receiving FA $48 \mathrm{~h}$ after surgery were excluded.

\section{Data collection}

The data filtering process was shown in Fig. 1. The information pertaining to demographics, past medical history, laboratory assessments, and hospital treatment has been reviewed. We searched medical records of all operation patients to collect the information of age, sex, preoperative hemoglobin $(\mathrm{Hb})$ and Scr on pre-operation, ASA grade, surgery time, anesthesia method, surgery grade, emergency surgery, FA using, intraoperative haemorrhage, intraoperative erythrocyte transfusion, in fluids amount and out fluids amount, in addition, the personal history was included to analyse (e.g. history of diabetes, hypertension, preoperative medication about ACE inhibitors, angiotensin receptor blockers (ARB), calcium Channel Blockers (CCB) and diuretics.

\section{Definition}

Postoperative AKI was diagnosed within 7 days after surgery based on changes in Scr, according to the Kidney Disease Improving Global Outcome criteria: a rise in Scr by $\geq 0.3 \mathrm{mg} / \mathrm{dl}$ within $48 \mathrm{~h}$ or an increase in $\mathrm{Scr} \geq 1.5$ times baseline within 7 days [14]. Scr before operation was defined as the lowest value obtained within 7 days prior to operation. KDIGO urine output criteria for AKI were not used since some patients received diuretic drugs during or after operation. We evaluated preoperative renal function by calculating the estimated glomerular filtration rate (eGFR). We used the four-variable Modification of Diet in Renal Disease (MDRD) formula to calculate eGFR $=175 \times$ Scr $^{1}{ }^{1.154} \times$ age $^{-0.203} \times 1.212$ (if black) $\times 0.742$ (if female). Preoperative chronic kidney disease (CKD) was defined as eGFR $\leqq 90 \mathrm{ml} / \mathrm{min} / 1.73 \mathrm{~m}^{2}$. According to the National Nosocomial Infection Surveillance (NNIS) index, the surgery was divided into four grades (NNIS 0, NNIS1, NNIS 2, NNIS3) [15]. Different anesthesia techniques including general anesthesia and intraspinal anesthesia were used for these patients. According to American society of Anesthesiologists physical status classfication system, ASA grade was divided into grade I to grade V. Out fluids amount was defined as intraoperative blood loss and urine output. In fluids amount was defined as the intraoperative transfusion volume of blood and fluid. Net fluid input is defined as the subtraction between in fluids amount and out fluids amount. The dose of FA was the cumulative dosage from the beginning of anesthesia to $48 \mathrm{~h}$ after surgery.

\section{Statistical analysis}

Statistical analyses were performed using the SPSS software, version 24.0 for windows program. The continuous results were expressed as mean values \pm standard deviation $(\bar{x} \pm \mathrm{SD})$, while the absolute and relative values (\%) were presented for categorical dates. Data of baseline characteristics were analyzed using $t$-test or one-way ANOVA for continuous variables, while $x^{2}$ test and Fisher's exact test was used for categorical variables. We used Least Significant Difference (LSD) t-test and Student-Newman-Keuls test for post-hoc analyses after one-way ANOVA compare to assess the differences of FA use among 4 groups. The logistic regression analysis was used to identify univariable and multivariable predictors for AKI. The adjusted relationship between FA and AKI was then modelled using multivariable logistic regression with adjustment for a priori selected risk factors for AKI. We reported adjusted odds ratios and associated $95 \% \mathrm{CIs}$ and $p$ values. All statistical tests were two-tailed, and $p<0.05$ was considered significant.

\section{Results}

\section{Comparison of clinical characteristics among patients} with and without AKI

During the 6-years study period, 9915 operation patients were included in this study. Of these 9915 patients, 662 (6.7\%) developed AKI as defined by the KDIGO criteria. In 662 AKI subjects and 9253 non AKI individuals, there were significant difference between the rate of preoperative hemoglobin, preoperative CKD, hypertension, diabetes, emergency surgery, surgery grade, intraoperative erythrocyte transfusion and intraoperative haemorrhage (all $p<0.001$ ). In AKI group, the rate of patients who used ACE inhibitors, $\mathrm{ARB}$, diuretics or $\mathrm{CCB}$ preoperatively were higher than those in non AKI group $(P=0.006, P<0.001, p=0.001, p<0.001$, respectively). In addition, there was a significant difference between AKI group and non-AKI group in the rate of male, age, general anesthesia and out fluids amount $(p=0.006, p=$ $0.048, p=0.011, p=0.037$, respectively). While there was no difference about surgery time and in fluids amount in these two groups ( $p=0.393, p=0.769$, respectively). The rate of ASA grade I, grade II and grade III in AKI group was similar compared with non AKI group $(p=0.122)$. There was no difference between AKI group and no AKI group about cumulative dose of FA and net net fluid input $(p=0.203, p=$ 0.156 , respectively) (Table 1 ).

\section{The relationship between different dose of flurbiprofen axetil and AKI}

Based on the cumulative dose of FA from the beginning of anesthesia to $48 \mathrm{~h}$ after surgery, the patients was divided into four groups: non use group was defined as not using FA, low dose group was defined as 50 to 100 $\mathrm{mg}$, the middle dose group was defined as $150 \mathrm{mg}$ to $200 \mathrm{mg}$, while the large dose group was defined as no less than $250 \mathrm{mg}$. As shown in Table 2, the rate of AKI was $7.2 \%$ in non use group, in 2246 subjects using FA, the rate of AKI was 5.1\%. In addition, the rate of AKI 
Table 1 Comparison of clinical characteristics among patients with and without AKI

\begin{tabular}{|c|c|c|c|}
\hline Factors & $\begin{array}{l}\text { Non AKI group } \\
(n=9253)\end{array}$ & $\begin{array}{l}\text { AKI group } \\
(n=662)\end{array}$ & $P$-value \\
\hline \multicolumn{4}{|l|}{ Fundamental state } \\
\hline Male, n (\%) & $4299(46.5)$ & $271(40.9)$ & 0.006 \\
\hline Age (Year) & $52.8 \pm 14.5$ & $53.9 \pm 14.2$ & 0.048 \\
\hline Preoperative hemoglobin ( $\mathrm{g} / \mathrm{dL})$ & $9.0 \pm 5.2$ & $8.1 \pm 5.2$ & $<0.001$ \\
\hline Hypertension, n(\%) & $1942(21.0)$ & $186(28.1)$ & $<0.001$ \\
\hline Diabetes, n (\%) & $580(6.3)$ & $70(10.6)$ & $<0.001$ \\
\hline pre-operative chronic kidney disease,n(\%) & $600(6.5)$ & 90 (13.6) & $<0.001$ \\
\hline Preoperative serum creatinine, $(\mu \mathrm{mol} / \mathrm{L})$ & $87.2 \pm 113.0$ & $92.2 \pm 110.4$ & 0.271 \\
\hline \multicolumn{4}{|l|}{ Preoperative medication } \\
\hline ACE inhibitors, n (\%) & $438(4.7)$ & $47(7.1)$ & 0.006 \\
\hline ARB, n (\%) & $274(3.0)$ & $40(6.0)$ & $<0.001$ \\
\hline CCB, n (\%) & $2266(24.5)$ & $267(40.3)$ & $<0.001$ \\
\hline Diuretics, n (\%) & $158(1.7)$ & $23(3.5)$ & 0.001 \\
\hline \multicolumn{4}{|l|}{ Surgery-related factors } \\
\hline In fluids amount (10 ml/24 h) & $1142.1(625.0-1542.7)$ & $958.8(625.0-1533.9)$ & 0.769 \\
\hline Out fluids amount (10 ml/24h) & $333.3(145.8-604.7)$ & $312.5(125.0-604.2)$ & 0.037 \\
\hline Emergency, n(\%) & $1136(12.3)$ & $144(21.8)$ & $<0.001$ \\
\hline General anesthesia, n (\%) & $7684(83.0)$ & $575(86.9)$ & 0.011 \\
\hline ASA Grade: & & & 0.122 \\
\hline I & $666(7.2)$ & $50(7.6)$ & \\
\hline$\|$ & $5949(64.3)$ & $400(64.0)$ & \\
\hline III & $2638(28.5)$ & $212(32.0)$ & \\
\hline Surgery grade, n (\%) & & & $<0.001$ \\
\hline 0 & $480(5.2)$ & $24(3.6)$ & \\
\hline 1 & $3222(34.8)$ & $246(37.2)$ & \\
\hline 2 & $5284(57.1)$ & $352(53.2)$ & \\
\hline 3 & $267(2.9)$ & $40(6.0)$ & \\
\hline Surgery time, n (\%) & & & 0.393 \\
\hline$<2 \mathrm{~h}$ & $3283(35.5)$ & $252(38.1)$ & \\
\hline $2 \mathrm{~h}-5 \mathrm{~h}$ & $5009(54.1)$ & $346(52.3)$ & \\
\hline$>5 \mathrm{~h}$ & $961(10.4)$ & $64(9.7)$ & \\
\hline Intraoperative Erythrocyte transfusion, ml (\%) & & & $<0.001$ \\
\hline$<100$ & $6825(73.8)$ & $426(64.4)$ & \\
\hline $100-600$ & $956(10.3)$ & $75(11.3)$ & \\
\hline $601-1000$ & $716(7.7)$ & $61(9.2)$ & \\
\hline$>1000$ & $756(8.2)$ & $100(15.1)$ & \\
\hline Intraoperative haemorrhage, ml (\%) & & & $<0.001$ \\
\hline$<100$ & $2578(27.9)$ & $224(33.8)$ & \\
\hline $101-600$ & $4905(53.0)$ & $296(44.7)$ & \\
\hline $601-1000$ & $818(8.8)$ & $51(7.7 \%)$ & \\
\hline$>1000$ & $952(10.3)$ & $91(13.7 \%)$ & \\
\hline Cumulative dose of flurbiprofen axetil, (mg) & $22.9 \pm 47.5$ & $20.5 \pm 53.8$ & 0.203 \\
\hline Net fluid input $(10 \mathrm{ml} / 24 \mathrm{~h})$ & $706.6 \pm 425.4$ & $682.0 \pm 450.0$ & 0.156 \\
\hline
\end{tabular}


Table 2 The relationship between different dose of flurbiprofen axetil (FA) and AKI

\begin{tabular}{|c|c|c|c|c|c|}
\hline Dose (mg) & Number (n) & Non AKI (n) & AKI $(n)$ & Rate of AKI (\%) & $P^{*}$ \\
\hline All patients & 9915 & 9253 & 662 & 6.7 & \\
\hline Non use & 7469 & 6932 & 537 & 7.2 & \\
\hline Use of FA & 2446 & 2321 & 125 & 5.1 & \\
\hline Low dose & 1920 & 1833 & 87 & 4.5 & $<0.001$ \\
\hline Middle dose & 462 & 436 & 26 & 5.6 & 0.355 \\
\hline Large dose & 64 & 52 & 12 & 18.8 & $<0.001$ \\
\hline
\end{tabular}

Note: $\mathrm{P}^{*}$ : compared with the group of not using flurbiprofen axetil. AKI: acute kidney injury

was significantly decreased to $4.5 \%$ in 1920 patients using FA at a dose of 50 to $100 \mathrm{mg}$, which was significantly less than that of non use group $(p<0.001)$. However, there was no significant difference between patients without using FA and subjects using FA at a dose of $150 \mathrm{mg}$ or $200 \mathrm{mg}$ ( $p=0.355)$. On the contrary, in the subjects using FA at a dose of $250 \mathrm{mg}$ or more, the rate of AKI was significantly increased to $18.8 \%$, which was significantly higher than that in non use group $(p<0.001)$.

\section{Comparison of clinical characteristics among patients using different dose of flurbiprofen axetil}

As shown in Table 3, we found significant differences among patients using different dose of FA in the rate of male, age, hypertension, preoperative CKD (all $p<0.001$ ), ASA grade $(p=0.001)$, general anesthesia $(p=0.006)$, preoperative medication of ACE inhibitor, CCB (all $p<0.001$ ), ARB ( $p=$ $0.003)$, and diuretics $(p<0.001)$. In addition, we also found that the factors of emergency operation, in fluids amount, out fluids amount, surgery grade, surgery time, intraoperative erythrocyte transfusion, and intraoperative haemorrhage were different $(p<0.05)$. Finally, there was no difference in preoperative hemoglobin $(p=0.16)$ and the rate of diabetes (0.071) among the patients using different dose of FA.

\section{Comparison of odds ratios of acute kidney injury across different dose group of flurbiprofen axetil by multivariate regression analysis}

As shown in Table 4, multivariate regression analysis was performed to compare the odds ratio between the dose of FA and the incidence of acute kidney injury. After adjusting various interference factors based on three different models, we found that low dose of FA was protective factor for acute kidney injury $(\mathrm{OR}=0.75$, $p=0.0188)$, and large dose of FA was risk factor for acute kidney injury $(\mathrm{OR}=4.8, p<0.0001)$ 。

Compare of odds ratios of acute kidney injury across different dose group of flurbiprofen axetil by ordinal logistic regression analysis

According to the Kidney Disease Improving Global Outcome(KDIGO)criteria, AKI is divided into three grades.
Grade 1: serum creatinine increased by $\geq 0.3 \mathrm{mg} / \mathrm{dl}$ within $48 \mathrm{~h}$ or increased 1.5-1.9 times baseline during 7 days. Grade 2: serum creatinine increased 2.0-2.9 times baseline. Grade 3: serum creatinine increased $\geq 3$ times baseline or serum creatinine increased to $4.0 \mathrm{mg} / \mathrm{dl}$ $(353.6 \mu \mathrm{mol} / \mathrm{L})$ or initiation of renal replacement therapy. We divided the patients into three groups according to the stages of AKI:stage $0=$ no AKI, stage $1=\mathrm{AKI}$ grade 1 , stage $2=$ AKI grade2 and 3 . As shown in Table 5, ordinal logistic regression analysis was performed to compare the odds ratio between the dose of FA and the incidence of acute kidney injury. After adjusting various interference factors based on three different models, we found that low dose of FA was protective factor for acute kidney injury, and large dose of FA was risk factor for acute kidney injury.

\section{Discussion}

It was reported that the rate of AKI was approximately $6.3-7.4 \%$ in patients who underwent noncardiac surgery $[2,3]$. Similar to the above results, 662 patients $(6.7 \%)$ developed AKI in our patients undergoing noncardiac surgery or nonurologic surgery.

The pathogenesis of postoperative AKI is complex and multifactorial. The use of nephrotoxic drugs was an important contributor for postoperative AKI, which has been demonstrated previously [6]. NSAIDs are the cornerstone of pain management in patients who have acute pain (eg, postoperative pain) for their analgesic and anti-inflammatory effects [16]. As a kind of targeted NSAIDs, intravenous administration of FA has been often used to reduce perioperative pain. Previous studies have explored the impact of FA on renal injury. However, the findings are controversial. Colome et al. found that FA could lead to renal papillary necrosis [11]. Similarly, Kaufhold et al. reported that a case of acute tubulointerstitial nephritis induced by FA [12]. Conversely, some animal experiments have indicated that FA could ameliorate renal injury in the rats with 5/6 kidney ablation $[9,10]$. Further study identified that the impact of long-term FA application on renal injury was small and subclinical [13]. These findings indicated that the relationship between FA and kidney injury need to be 
Table 3 Comparison of clinical characteristics among the patients using different dose of flurbiprofen axetil

\begin{tabular}{|c|c|c|c|c|c|}
\hline Factors & $\begin{array}{l}\text { Non Use group } \\
(n=7469)\end{array}$ & $\begin{array}{l}\text { Low dose group } \\
(n=1920)\end{array}$ & $\begin{array}{l}\text { Middle dose group } \\
(n=462)\end{array}$ & $\begin{array}{l}\text { Large dose group } \\
(n=64)\end{array}$ & $P$ \\
\hline \multicolumn{6}{|l|}{ Fundamental state } \\
\hline Male, n (\%) & $3355(44.9)$ & $966(50.3)$ & $217(47.0)$ & $32(50.0)$ & $<0.001$ \\
\hline Age (Year) & $53.6 \pm 14.7$ & $50.8 \pm 13.4$ & $50.8 \pm 13.8$ & $49.5 \pm 15.7$ & $<0.001$ \\
\hline Preoperative hemoglobin ( $\mathrm{g} / \mathrm{dl}$ ) & $8.9 \pm 5.2$ & $9.2 \pm 5.3$ & $9.0 \pm 5.3$ & $9.7 \pm 5.6$ & 0.16 \\
\hline Hypertension, n (\%) & $1728(23.1)$ & $319(16.6)$ & $75(16.2)$ & $9(14.1)$ & $<0.001$ \\
\hline Preoperative serum creatinine, $(\mu \mathrm{mol} / \mathrm{L})$ & $91.7 \pm 122.4$ & $75.2 \pm 74.8$ & $74.2 \pm 80.7$ & $70.8 \pm 43.1$ & $<0.001$ \\
\hline Diabetes, n (\%) & $510(6.8)$ & $102(5.3)$ & $35(7.6)$ & $3(4.7)$ & 0.071 \\
\hline preoperative chronic kidney disease, n (\%) & $586(7.8)$ & $87(4.5)$ & $15(3.2)$ & $2(3.1)$ & $<0.001$ \\
\hline ASA Grade, n (\%) & & & & & 0.001 \\
\hline । & $511(6.8)$ & $155(8.1)$ & $44(9.5)$ & $6(9.4)$ & \\
\hline$\|$ & $4733(63.4)$ & $1285(66.9)$ & $288(62.3)$ & $43(67.2)$ & \\
\hline III & 2225 (29.8) & $480(25.0)$ & $130(28.1)$ & $15(23.4)$ & \\
\hline \multicolumn{6}{|l|}{ Preoperative medication } \\
\hline ACE inhibitors, n (\%) & $407(5.4)$ & $62(3.2)$ & $13(2.8)$ & $3(4.7)$ & $<0.001$ \\
\hline ARB, n (\%) & $262(3.5)$ & $39(2.0)$ & $13(2.8)$ & $0(0.0)$ & 0.003 \\
\hline CCB, n (\%) & 2095 (28.0) & $348(18.1)$ & $84(18.2)$ & $6(9.4)$ & $<0.001$ \\
\hline Diuretics, n (\%) & $160(2.1)$ & $17(0.9)$ & $4(0.9)$ & $0(0.0)$ & $<0.001$ \\
\hline \multicolumn{6}{|l|}{ Surgery-related factors } \\
\hline In fluids amount & 1041.7 & 1041.7 & 1333.3 & 1292.1 & 0.029 \\
\hline$(10 \mathrm{ml} / 24 \mathrm{~h})$ & $(625.0-1520.8)$ & $(666.7-1500.0)$ & $(875.0-1750.0)$ & $(875.0-1692.7)$ & \\
\hline Out fluids amount & 333.3 & 333.3 & 416.7 & 371.9 & 0.028 \\
\hline$(10 \mathrm{ml} / 24 \mathrm{~h})$ & $(125.0-600.0)$ & $(166.7-583.3)$ & $(229.2-708.3)$ & (208.3-614.6) & \\
\hline Emergency, n (\%) & 1065 (14.3) & $169(8.8)$ & $41(8.9)$ & $5(7.8)$ & $<0.001$ \\
\hline General anesthesia, n (\%) & $6175(82.7)$ & $1623(84.5)$ & $408(88.3)$ & $53(82.8)$ & 0.006 \\
\hline Surgery grade, n (\%) & & & & & $<0.001$ \\
\hline 0 & $425(5.7)$ & $72(3.8)$ & $6(1.3)$ & $1(1.6)$ & \\
\hline 1 & $2581(34.6)$ & $744(38.8)$ & $126(27.3)$ & $17(26.6)$ & \\
\hline 2 & $4211(56.4)$ & $1061(55.3)$ & $320(69.3)$ & $44(68.8)$ & \\
\hline 3 & $252(3.4)$ & $43(2.2)$ & $10(2.2)$ & $2(3.1)$ & \\
\hline Surgery time, $\mathrm{n}(\%)$ & & & & & $<0.001$ \\
\hline$<2 \mathrm{~h}$ & $2845(38.1)$ & $595(31.0)$ & $79(17.1)$ & $16(25.0)$ & \\
\hline $2 \mathrm{~h}-5 \mathrm{~h}$ & $3870(51.8)$ & $1125(58.6)$ & $321(69.5)$ & $39(60.9)$ & \\
\hline$>5 \mathrm{~h}$ & $754(10.1)$ & $200(10.4)$ & $62(13.4)$ & $9(14.1)$ & \\
\hline Intraoperative erythrocyte transfusion, $\mathrm{ml}(\%)$ & & & & & $<0.001$ \\
\hline$<100$ & $5409(72.4)$ & $1491(77.7)$ & $307(66.5)$ & $44(68.8)$ & \\
\hline $100-600$ & $782(10.5)$ & $183(9.5)$ & $56(12.1)$ & $10(15.6)$ & \\
\hline $601-1000$ & $603(8.1)$ & $123(6.4)$ & $45(9.7)$ & $6(9.4)$ & \\
\hline$>1000$ & $675(9.0)$ & $124(6.5)$ & $54(11.7)$ & $4(6.3)$ & \\
\hline Intraoperative haemorrhage,ml (\%) & & & & & $<0.001$ \\
\hline$<100$ & $2269(30.4)$ & $487(25.4)$ & $41(8.9)$ & $5(7.8)$ & \\
\hline $100-600$ & 3796 (50.8) & $1056(55.0)$ & $307(66.5)$ & $42(65.6)$ & \\
\hline $601-1000$ & $635(8.5)$ & $187(9.7)$ & $41(8.9)$ & $6(9.4)$ & \\
\hline$>1000$ & 769 (10.3) & $190(9.9)$ & 73 (15.8) & $11(17.2)$ & \\
\hline
\end{tabular}


Table 4 Comparison of odds ratios of AKI across different dose group of flurbiprofen axetil by multivariate regression analysis

\begin{tabular}{llll}
\hline Groups & Model 1 P & Model 2 P & Model 3 P \\
\hline Non-use & 1 & 1 & 1 \\
Low dose group $(50-100 \mathrm{mg})$ & $0.61(0.48,0.77)<0.0001$ & $0.71(0.56,0.90) 0.0042$ & $0.75(0.59,0.95) 0.0188$ \\
Middle dose group $(150-200 \mathrm{mg})$ & $0.80(0.54,1.19) 0.2689$ & $0.92(0.61,1.39) 0.6847$ & $0.99(0.65,1.49) 0.9489$ \\
Large dose group $(\geq 250 \mathrm{mg})$ & $2.98(1.58,5.62) 0.0007$ & $4.15(2.18,7.90)<0.0001$ & $4.80(2.49,9.26)<0.0001$ \\
\hline
\end{tabular}

Model 1:Non-adjusted

Model 2:adjusted for age, sex, preoperative hemoglobin, hypertension, diabetes, use of ACE inhibitors, CCB and diuretics, general anesthesia, emergency, ASA grade, surgery grade, in fluids amount, out fluids amount. Hosmer-Lemeshougoodness test: $P=0.295$

Model 3: adjusted for age, sex, preoperative hemoglobin, hypertension, diabetes, use of ACE inhibitors, ARB, CCB and diuretics, general anesthesia, emergency, ASA grade, surgery grade, in fluids amount, out fluids amount, surgery time, intraoperative erythrocyte transfusion, intraoperative haemorrhage and preoperative chronic kidney disease. Hosmer-Lemeshou goodness test: $P=0.123$

Note: AKI acute kidney injury, ASA American Society of Anesthesiologists

further explored, and whether different dose of FA will generate beneficial or detrimental effects on AKI is unclear.

In this large single-center retrospective study, we explored the exact effects of FA on postoperative AKI, as a matter of fact, the subjects in the group of not using FA did not use any other NSAIDs for reducing postoperative pain, and for the first time we found that the impact of FA on postoperative AKI was dose-dependent, using of low dose of FA (50-100 mg) perioperatively was significantly associated with decreased incidence of postoperative AKI. This finding was opposed to the traditional concept: NSAIDs was an important cause of AKI both in children and adults $[17,18]$.

The mechanisms responsible for the different biological effect on renal function depending on different dose of FA is unclear. Large dose of FA may inhibit COX, interfering on arachidonic acid conversion into prostaglandins, reducing renal blood flow, causing tubular obstruction through crystal deposition, and inducing direct cytotoxicity or cell-mediated immune injury. It was reported that FA could induce renal papillary necrosis [11], and acute tubulointerstitial nephritis [12]. Hence, large dose of NSAIDs have been implicated as causes of AKI, especially in the elderly. What we were more interested in was that low dose of FA perioperatively maybe an independent protective factor for postoperative AKI. It has been reported that increased renal expression of COX1 and COX2 in various nephropathies (e.g. lupus nephritis, heymann nephritis and renal ablation) [19-21]. COX derivatives may play an important role in the pathogenesis of progressive nephropathies. The potential role of prostanoids in the pathogenesis of progressive nephropathies has long been acknowledged. The stimulation of podocytes by complement fractions can increase the local synthesis of prostanoids. Similarly, non-immune mechanisms such as mesangial stretching can augment the expression of COX and enhance the production of its derivatives [22]. Accordingly, studies of the 5/6 renal ablation model showed increased urinary excretion of prostanoids per nephron [23]. It has been found that increased production of prostanoids can enhance inflammation and, therefore, accelerate renal injury. Goncalves et al. found that COX-2 could mediate inflammation and structural injury in the glomeruli [10]. In addition, part of the renal injury secondary to operation is a consequence of the inflammatory response with involvement of COX-2 and prostaglandins, the production and secretion of chemokines and cytokines (e.g. IL-1, IL- 6 and TNF- $\alpha$ ). So we speculated that low dose of FA could exert renal protective effects via reducing the inflammatory effects on the kidney [24, 25]. In addition, surgery and pain per se could result in activation of the renin-angiotensin system (RAS) and increased secretion of antidiuretic hormone, ultimately lead to hemodynamics abnormality [26, 27]. FA could alleviate pain, which maybe result in the restoration of the RAS and renal hemodynamics. What's more, because of high affinity for inflammatory tissues, low dose of FA could accumulate mainly in surgical incision and inflammatory site and exert minor effect on the kidney. Further in vivo and in vitro study will be necessary to confirm this.

Because of a variety of reasons, there still exist several drawbacks in this study. First, our study enrolled all patients in a single center and thus external validity is limited. Second, AKI was determined according to the KDIGO criteria using the change in Scr in the present study, accurate urine output data at the general ward were not available. Although most of the previous studies did not use urine output criteria to diagnose AKI, the incidence of AKI might be changed if it is included. Third, we have excluded 58,996 patients who had missing data of Scr and urine volume, and the missing data might be from these patients who had low risk for developing AKI, therefore, this may reduce the accuracy of AKI incidence rate in the group of not using FA. Fourthly, the retrospective study design precludes the suggestion of any causal interference. Bias from unknown or unmeasured confounders may have influenced 
Table 5 Compare of Odds Ratios of Acute Kidney Injury across different dose group of flurbiprofen axetil by ordinal logistic regression analysis

\begin{tabular}{llll}
\hline Groups & Model 1 & Model 2 & Model 3 \\
& $P$ & $P$ & $P$ \\
\hline Non-use & 0 & 0 & 0 \\
Low dose group & $-0.0396(-0.0587,-0.0204)$ & $-0.0117(-0.0215,-0.0019)$ & $-0.0194(-0.0385,-0.0003)$ \\
(50-100 mg) & $<0.0001$ & 0.0198 & 0.0463 \\
Middle dose group & $-0.0262(-0.0621,-0.0096)$ & $-0.0025(-0.0208,-0.0158)$ & $-0.0064(-0.0419,0.0292)$ \\
(150-200 mg) & 0.1513 & 0.7908 & 0.7260 \\
Large dose group & $0.1458(0.0520,0.2397)$ & $0.0991(0.0504,0.1477)$ & $0.1834(0.0910,0.2758)$ \\
( $\geq 250$ mg) & 0.0023 & $<0.0001$ & 0.0001 \\
\hline
\end{tabular}

\section{Model 1: Non-adjusted}

Model 2: adjusted for age, sex, preoperative hemoglobin, hypertension, diabetes, use of ACE inhibitors, CCB and diuretics, general anesthesia, emergency, ASA grade, surgery grade, in fluids amount, out fluids amount

Hosmer-Lemeshou goodness test: $P=0.279$

Model 3: adjusted for age, sex, preoperative hemoglobin, hypertension, diabetes, use of ACE inhibitors, ARB, CCB and diuretics, general anesthesia, emergency, ASA grade, surgery grade, in fluids amount, out fluids amount, surgery time, intraoperative erythrocyte transfusion, intraoperative haemorrhage and preoperative chronic kidney disease

Hosmer-Lemeshou goodness test: $P=0.121$

Note: AKI: acute kidney injury; We divided the patients into three groups according to the stages of AKI:stage $0=$ no AKI, stage $1=\mathrm{AKI}$ grade 1 , stage $2=\mathrm{AKI}$ grade2 and 3

ASA American Society of Anesthesiologists

the results. In addition, due to a retrospective study and the large number of patients, it was difficult to collect the data such as the type of infusion liquid, vasopressors, contrast, proton pump inhibitor and intraoperative blood pressure, which may be the risk factors for AKI $[28,29]$. The fifth, although we excluded cardiac and urologic surgery, we did not take the other type of surgery into account. All these can affect the use of FA and/or AKI. Finally, randomized controlled trials are needed to verify the effects of low-dose FA on AKI.

\section{Conclusion}

In conclusion, our study showed for the first time that the impact of FA on postoperative AKI was dose-dependent, using of low dose FA (50-100 mg) perioperatively may effectively reduce the incidence of postoperative AKI. However, further animal experiment and multicentric large prospective studies will be needed to confirm this point.

\section{Abbreviations}

AKI: Acute kidney injury; ARB: Angiotensin receptor blockers; ASA: Anesthesiologists; CCB: Calcium Channel Blockers; CKD: Chronic kidney disease; COX: Cyclooxygenase; eGFR: Estimated glomerular filtration rate; FA: Flurbiprofen axetil; Hb: Hemoglobin; KDIGO: Kidney Disease Improving Global Outcome; LSD: Least significant difference; MDRD: Modification of Diet in Renal Disease; NNIS: National nosocomial infection surveillance; NSAIDs: Nonsteroidal anti-inflammatory drugs; RAS: Renin-angiotensin system; Scr: Serum creatinine

\section{Acknowledgements}

We thank Dr. Xing Liu for excellent technical assistance with the data filtering.

\section{Authors' contributions}

DW, SKY, MXZ and YZT performed data analysis, DW, SKY wrote the manuscript, WOY edited the manuscript, $\mathrm{HZ}$ and QL designed the research. $\mathrm{QL}, \mathrm{SKY}$ and $\mathrm{HZ}$ acquired funding for this research. All authors have read and approved the manuscript.

\section{Funding}

This study was supported by the National Natural Sciences Foundation of China (NO.81870498,81500558), Natural Sciences Foundation of Hunan province (2018JJ3785) and by the New Xiangya talent projects of the third Xiangya hospital of Central South University (20180303). The funders had no role in study design, data collection and analysis,

decision to publish or preparation of the manuscript.

\section{Availability of data and materials}

The data used to support the findings of this study are available from the first author and corresponding author upon reasonable request.

\section{Ethics approval and consent to participate}

This study was in line with the guidelines of the Strengthening of Observational Epidemiological Studies (STROBE) statement [30], in accordance with the Helsinki declaration, and approved by the ethics committee of the third Xiangya hospital of Central South University (2018-S376). Because of retrospective study, informed consent was waived, in order to access the medical records of patients, we need the permission of Big data analysis center of the Third Xiangya hospital of Central South University.

\section{Consent for publication}

Not Applicable.

\section{Competing interests}

The authors declare that they have no competing interests.

\section{Author details}

'Department of Anesthesiology, The Third Xiangya Hospital of Central South University, 138, Tongzipo Road, Changsha, Hunan, China. ${ }^{2}$ Department of Nephrology, The Third Xiangya Hospital of Central South University, Changsha, Hunan, China.

Received: 27 September 2019 Accepted: 5 February 2020

Published online: 14 February 2020

\section{References}

1. Bellomo R, Kellum JA, Ronco C. Acute kidney injury. Lancet. 2012;380(9843): 756-66.

2. Walsh M, Devereaux PJ, Garg AX, Kurz A, Turan A, Rodseth RN, Cywinski J, Thabane L, Sessler DI. Relationship between intraoperative mean arterial pressure and clinical outcomes after noncardiac surgery: toward an empirical definition of hypotension. Anesthesiology. 2013;119(3):507-15. 
3. Sun LY, Wijeysundera DN, Tait GA, Beattie WS. Association of intraoperative hypotension with acute kidney injury after elective noncardiac surgery. Anesthesiology. 2015;123(3):515-23.

4. Vanmassenhove J, Kielstein J, Jorres A, Biesen W. Management of patients at risk of acute kidney injury. Lancet. 2017;389(10084):2139-51.

5. Gameiro J, Fonseca JA, Neves M, Jorge S, Lopes JA. Acute kidney injury in major abdominal surgery: incidence, risk factors, pathogenesis and outcomes. Ann Intensive Care. 2018;8(1):22.

6. Zhang $Y$, Jiang $L$, Wang $B, X i X$. Epidemiological characteristics of and risk factors for patients with postoperative acute kidney injury: a multicenter prospective study in 30 Chinese intensive care units. Int Urol Nephrol. 2018; 50(7):1319-28.

7. Wang K, Luo J, Zheng L, Luo T. Preoperative flurbiprofen axetil administration for acute postoperative pain: a meta-analysis of randomized controlled trials. J Anesth. 2017:31(6):852-60.

8. Wongrakpanich S, Wongrakpanich A, Melhado K, Rangaswami J. A comprehensive review of non-steroidal anti-inflammatory drug use in the elderly. Aging Dis. 2018;9(1):143-50.

9. Fujihara CK, Malheiros DM, Donato JL, Poli A, De Nucci G, Zatz R. Nitroflurbiprofen, a new nonsteroidal anti-inflammatory, ameliorates structural injury in the remnant kidney. Am J Phys. 1998:274(3):F573-9.

10. Goncalves AR, Fujihara CK, Mattar AL, Malheiros DM, Noronha Ide L, de Nucci G, Zatz R. Renal expression of COX-2, ANG II, and AT1 receptor in remnant kidney: strong renoprotection by therapy with losartan and a nonsteroidal anti-inflammatory. Am J Physiol Renal Physiol. 2004;286(5):F945-54.

11. Colome Nafria E, Solans R, Espinach J, Delgadillo J, Fonollosa V. Renal papillary necrosis induced by flurbiprofen. DICP. 1991;25(7-8):870-1.

12. Kaufhold J, Wilkowski M, McCabe K. Flurbiprofen-associated acute tubulointerstitial nephritis. Am J Nephrol. 1991;11(2):144-6.

13. Otsuka N, Yataba I, Matsushita I, Matsumoto H, Hoshino Y, Terada Y. A minimal impact of long-term S-flurbiprofen plaster application on kidney function in osteoarthritis patients. Clin Exp Nephrol. 2017:21(6):1060-7.

14. Okusa MD, Davenport A. Reading between the (guide)lines--the KDIGO practice guideline on acute kidney injury in the individual patient. Kidney Int. 2014;85(1):39-48.

15. Emori TG, Culver DH, Horan TC, Jarvis WR, White JW, Olson DR, Banerjee S, Edwards JR, Martone WJ, Gaynes RP, et al. National nosocomial infections surveillance system (NNIS): description of surveillance methods. Am J Infect Control. 1991;19(1):19-35.

16. Sehajpal S, Prasad DN, Singh RK. Prodrugs of non-steroidal antiinflammatory drugs (NSAIDs): a long march towards synthesis of safer NSAIDs. Mini Rev Med Chem. 2018;18(14):1199-219.

17. Dreischulte T, Morales DR, Bell S, Guthrie B. Combined use of nonsteroidal anti-inflammatory drugs with diuretics and/or renin-angiotensin system inhibitors in the community increases the risk of acute kidney injury. Kidney Int. 2015;88(2):396-403

18. Misurac JM, Knoderer CA, Leiser JD, Nailescu C, Wilson AC, Andreoli SP. Nonsteroidal anti-inflammatory drugs are an important cause of acute kidney injury in children. J Pediatr. 2013;162(6):1153-9 1159 e1151.

19. Takano T, Cybulsky AV. Complement C5b-9-mediated arachidonic acid metabolism in glomerular epithelial cells : role of cyclooxygenase-1 and -2 . Am J Pathol. 2000;156(6):2091-101.

20. Tomasoni S, Noris M, Zappella S, Gotti E, Casiraghi F, Bonazzola S, Benigni A Remuzzi G. Upregulation of renal and systemic cyclooxygenase-2 in patients with active lupus nephritis. J Am Soc Nephrol. 1998;9(7):1202-12.

21. Wang JL, Cheng HF, Zhang MZ, MCKanna JA, Harris RC. Selective increase of cyclooxygenase-2 expression in a model of renal ablation. Am J Phys. 1998; 275(4):F613-22.

22. Akai Y, Homma T, Burns KD, Yasuda T, Badr KF, Harris RC. Mechanical stretch/relaxation of cultured rat mesangial cells induces protooncogenes and cyclooxygenase. Am J Phys. 1994;267(2 Pt 1):C482-90.

23. Nath KA, Chmielewski DH, Hostetter TH. Regulatory role of prostanoids in glomerular microcirculation of remnant nephrons. Am J Phys. 1987;252(5 Pt 2):F829-37.

24. Feitoza CQ, Goncalves GM, Semedo P, Cenedeze MA, Pinheiro HS, Beraldo FC, dos Santos OF, Teixeira Vde P, dos Reis MA, Mazzali M, et al. Inhibition of COX 1 and 2 prior to renal ischemia/reperfusion injury decreases the development of fibrosis. Mol Med. 2008;14(11-12):724-30.

25. Calistro Neto JP, Torres Rda C, Goncalves GM, Silva LM, Domingues MA, Modolo NS, Barros GA. Parecoxib reduces renal injury in an ischemia/ reperfusion model in rats. Acta Cir Bras. 2015;30(4):270-6.
26. Sear JW. Kidney dysfunction in the postoperative period. Br J Anaesth. 2005; 95(1):20-32.

27. Carmichael $P$, Carmichael AR. Acute renal failure in the surgical setting. ANZ J Surg. 2003;73(3):144-53.

28. Klepser DG, Collier DS, Cochran GL. Proton pump inhibitors and acute kidney injury: a nested case-control study. BMC Nephrol. 2013;14:150.

29. Al-Aly Z, Maddukuri G, Xie Y. Proton pump inhibitors and the kidney: implications of current evidence for clinical practice and when and how to Deprescribe. Am J Kidney Dis. 2019. [Epub ahead of print].

30. von Elm E, Altman DG, Egger M, Pocock SJ, Gotzsche PC, Vandenbroucke $J P$. The strengthening the reporting of observational studies in epidemiology (STROBE) statement: guidelines for reporting observational studies. J Clin Epidemiol. 2008;61(4):344-9.

\section{Publisher's Note}

Springer Nature remains neutral with regard to jurisdictional claims in published maps and institutional affiliations.
Ready to submit your research? Choose BMC and benefit from:

- fast, convenient online submission

- thorough peer review by experienced researchers in your field

- rapid publication on acceptance

- support for research data, including large and complex data types

- gold Open Access which fosters wider collaboration and increased citations

- maximum visibility for your research: over $100 \mathrm{M}$ website views per year

At $\mathrm{BMC}$, research is always in progress.

Learn more biomedcentral.com/submissions 